\title{
Eastern Mediterranean region tuberculosis economic burden in 2014
}

\author{
A Sargazi ${ }^{1}$, Z Sepehri ${ }^{*}$, A Sagazi ${ }^{3}$, PK Nadakkavukaran Jim $^{4}$, Z Kiani $^{5}$ \\ From 3rd International Conference on Prevention and Infection Control (ICPIC 2015) \\ Geneva, Switzerland. 16-19 June 2015
}

\section{Introduction}

Tuberculosis (TB) is known one of reasons of human mortality to this date cause by Mycobacterium tuberculosis.

\section{Objectives}

In this study we tried to evaluate the direct economic burden of tuberculosis in the Eastern Mediterranean region in 2014 and determine its economic effect in the Gulf region.

\section{Methods}

In this descriptive analytical study, data gathered from World Health Organization global report and World Bank data sheet. We considered decrease of disabilityadjusted life year (DALY index) related to TB and its influence on gross domestic production (GDP) as TB economic burden. Data analyzed using SPSS software.

\section{Results}

GDP per capita was $\$ 665, \$ 24689, \$ 1668, \$ 3314, \$ 4763$, \$6862, \$5214, \$52197, \$9928, \$11965, \$3093, \$21929, \$1275, \$93714, \$25962, \$1753, \$4317, \$43049, \$1773 and \$0 USD for Afghanistan, Bahrain, Djibouti, Egypt, Iran, Iraq, Jordan, Kuwait, Lebanon, Libya, Morocco, Oman, Pakistan, Qatar, Saudi Arabia, Sudan, Tunisia, United Arab Emirates, Yemen and Syria respectively in 2013. Eastern Mediterranean Mean GDP per capita was about 16744 USD in 2013. Gross GDP was 3\% in Middle East in 2014, therefore Mean Eastern Mediterranean GDP per capita is calculated as 17246 USD for 2014.

Mean years of life expectancy at birth was 68 years, Tuberculosis weight was about 0.271 and TB incidence is considered in one year period. Mean years of life lost were 61 and 34 years for a child and an adult respectively. Number of TB infected cases was 750,000 and YLL, YLD and DALY is calculated as 5,138,000, 203,250 and $5,341,250$ years. Economic burden related to TB mortality and morbidity is calculated more than 92 billion dollars in Eastern Mediterranean region in 2014.

\section{Conclusion}

In this project we evaluated tuberculosis direct economic burden while indirect burden sometimes has more cost. The total money spent in tuberculosis care system was less than 250 million USD in Eastern Mediterranean region in 2014. According to TB high economic burden, We suggest to specialize sufficient budget for TB control in this region.

\section{Disclosure of interest}

None declared.

\section{Authors' details}

${ }^{1}$ Medical faculty, Zabol University of Medical Sciences, Zabol, Islamic Republic Of Iran. ${ }^{2}$ Research department, Zabol University of Medical Sciences, Zabol, Islamic Republic Of Iran. ${ }^{3}$ Civil faculty, Sistan and Baloochestan University, Zahedan, Islamic Republic Of Iran. ${ }^{4}$ Oracle eBusiness Department, Tech Mahindra, Linlithgow, UK. ${ }^{5}$ Medical faculty, Kerman medical university, Kerman, Islamic Republic Of Iran.

Published: 16 June 2015

\section{References}

1. World Health Organization: Global Tuberculosis Report 2013. World Health Organization; 2013.

2. Sullivan Sean D, Ramsey Scott D, Lee Todd A: The economic burden of COPD. CHEST Journal 2000, 117(2 Suppl):5S-9S.

\section{doi:10.1186/2047-2994-4-S1-P102}

Cite this article as: Sargazi et al.: Eastern Mediterranean region tuberculosis economic burden in 2014. Antimicrobial Resistance and Infection Control 2015 4(Suppl 1):P102.

${ }^{2}$ Research department, Zabol University of Medical Sciences, Zabol, Islamic Republic Of Iran

Full list of author information is available at the end of the article 